\title{
Dense Packing of Xenon in an Ultra-Microporous Metal-Organic Framework for Benchmark Xenon Capture and Separation
}

Qiang Liu

Hui-Min Wen

Youjin Gong

Jiyan Pei

Boyu Liu

Shunshun Xiong ( $\nabla$ ssxiong@caep.cn )

Bin Li ( $\nabla$ bin.li@zju.edu.cn )

https://orcid.org/0000-0002-7774-5452

Xiaolin Wang ( $\triangle$ xlwang@caep.cn )

\section{Research Article}

Keywords: porous materials, adsorptive separation, xenon, krypton, dense packing

Posted Date: January 17th, 2022

DOI: https://doi.org/10.21203/rs.3.rs-1266060/v1

License: @ (i) This work is licensed under a Creative Commons Attribution 4.0 International License.

Read Full License 
1 Dense Packing of Xenon in an Ultra-Microporous Metal-Organic Framework for Benchmark Xenon Capture and Separation

3 Qiang $\mathrm{Liu}^{1+}$, Hui-Min Wen ${ }^{2+}$, Youjing Gong ${ }^{1}$, Jiyan $\mathrm{Pei}^{3}$, Boyu Liu ${ }^{1}$, Shunshun Xiong ${ }^{1 *}$, Bin $\mathrm{Li}^{3^{*}}$ and $4 \quad$ Xiaolin Wang ${ }^{1 *}$

$5 \quad{ }^{1}$ Institute of Nuclear Physics and Chemistry, China Academy of Engineering Physics, Mianyang, Sichuan, China.

$6 \quad{ }^{2}$ College of Chemical Engineering, Zhejiang University of Technology, Hangzhou 310014, China.

$[+]$ These authors contributed equally to this work. 
For adsorptive separation of xenon/krypton mixture, it still remains a daunting challenge to target both high Xe adsorption and selectivity in a single adsorbent because of their close size and inert nature. Herein, we report an ultra-microporous alkyl Cu-based MOF (MOF-11) with suitable pore architecture for benchmark Xe capture and separation. MOF-11 features small pore channels ( $4.4 \AA$ ) close to the kinetic diameter of Xe atom, in which a large number of oppositely adjacent open $\mathrm{Cu}$-metal sites and alkyl cavities are densely arranged along the pore channels in staggered mode. Such unique pore system can not only introduce strong binding affinity with Xe, but also enable the dense packing of Xe inside the pores. This material thus shows the highest Xe storage density of $2826 \mathrm{~g} \mathrm{~L}^{-1}$ at ambient conditions, record-high Xe uptake of $4.0 \mathrm{mmol} \mathrm{g}^{-1}$ (at 0.2 bar and $298 \mathrm{~K}$ ) and one of the highest $\mathrm{Xe} / \mathrm{Kr}$ selectivity (19.1), significantly higher than most top-performing materials reported so far. The Xe molecules trapped within MOF-11 were visually identified by single-crystal X-ray diffraction experiment, which unveils the dense packing mechanism of Xe within the pores accountable for the record capacity $\left(3.46 \mathrm{mmol} \mathrm{g}^{-1}\right)$ and $\mathrm{Kr}$ productivity $\left(350 \mathrm{~cm}^{3} \mathrm{~g}^{-1}\right)$.

\section{INTRODUCTION}

Highly efficient and energy-saving separation of noble gases such as xenon (Xe) and krypton 
(Xe and $\mathrm{Kr}$ ) and the pollution control of their radioactive isotopes. High-purity $\mathrm{Xe}$ and $\mathrm{Kr}$ are commercially valuable and widely used in many applications including spacecraft propellants, insulation, lighting, medical imaging and gas lasers ${ }^{1}$. The main available resources of Xe and $\mathrm{Kr}$ come from the Earth atmosphere with the extremely low concentrations ( $0.087 \mathrm{ppmv}$ for $\mathrm{Xe}$ and $1.14 \mathrm{ppmv}$ for $\mathrm{Kr})^{2}$. Generally, commercial $\mathrm{Xe}$ and $\mathrm{Kr}$ gas are produced by cryogenic distillation from an approximately 20/80 (v/v) Xe/Kr gas mixture, which is obtained as a byproduct during air separation industry ${ }^{2}$. In addition, the radioactive ${ }^{127} \mathrm{Xe}$ and ${ }^{85} \mathrm{Kr}$ isotopes are generated in nuclear fission and can enter the atmosphere during the used nuclear fuel (UNF) reprocessing, which must be separated and sequestered safely to prevent the radioactive contamination since they are both hazardous and ${ }^{85} \mathrm{Kr}$ has a long half-life of 10.8 years ${ }^{3-5}$. Traditional cryogenic distillation is by far the most mature technology to separate $\mathrm{Xe}$ and $\mathrm{Kr}$ from air or the off-gas streams during the UNF reprocessing, which is excessively costly and energy-intensive ${ }^{4}$. To reduce energy consumption, the development of more efficient separation technologies is highly desired for $\mathrm{Xe} / \mathrm{Kr}$ separations.

Adsorptive separation using solid porous adsorbents has been considered as a more energyefficient alternative due to the potential of greatly cutting energy consumption and operating $\operatorname{costs}^{6}$. In this regard, porous metal-organic frameworks (MOFs) ${ }^{7-13}$, also known as porous coordination polymers (PCPs), have emerged as a new class of promising adsorbents for various gas separations owing to their highly tunable pore structures and functionalities ${ }^{14-24}$. While a number of MOFs have been developed for efficient $\mathrm{Xe} / \mathrm{Kr}$ separation ${ }^{25-51}$, it still remains a grand challenge to target ultrahigh separation performance, since $\mathrm{Xe}$ and $\mathrm{Kr}$ are inert atomic gases with no dipole or quadrupole moments. Typically, there exists an obvious trade- 
off between adsorption uptake and gas selectivity for $\mathrm{Xe} / \mathrm{Kr}$ separation ${ }^{27}$. For example, some large-pore MOFs (e.g., PCN-14 and HKUST) $)^{25,35}$ exhibit high Xe adsorption capacity at 1 bar but weak Xe binding affinity that cannot efficiently discriminate the two molecules, thus resulting in low $\mathrm{Xe} / \mathrm{Kr}$ selectivity. On the other hand, some ultra-microporous MOFs with tailor-made pore size that is slightly larger than the kinetic diameter of Xe (4.047 $\AA$ ), usually exhibit the strong Xe binding affinity due to the pore confinement effect induced by the overlap of van der Waals potentials, leading to the record high $\mathrm{Xe} / \mathrm{Kr}$ selectivity reported so far. However, their small pore volumes or low surface areas prone to result in relatively low Xe uptake capacities, as exemplified by SBMOF-1 $1^{31}$ and Co-squarate ${ }^{32}$. To overcome this tradeoff limitation, a better design is to construct suitable pore confinement densely decorated with strong binding sites in ultra-microporous MOFs, enabling highly selective recognition and efficient packing of targeted Xe molecules inside the pores. Thus, the strong binding sites can strengthen the recognition of $\mathrm{Xe}$ over $\mathrm{Kr}$ and thus improve $\mathrm{Xe} / \mathrm{Kr}$ selectivity; meanwhile, the dense packing of the preferred Xe molecules is able to fully make use of pore spaces for high Xe uptake density. This strategy has been well exemplified in the MOFs of SIFSIX-1-Cu ${ }^{14}$ and UTSA- $16^{23}$ for $\mathrm{C}_{2} \mathrm{H}_{2}$ or $\mathrm{CO}_{2}$ capture and separation, wherein the suitable pore confinement enables the formation of gas clusters inside the pores to result in the dense packing of gas molecules for targeting simultaneously high gas uptake and selectivity. However, compared with those gases with dipole or quadrupole moments (e.g., $\mathrm{CO}_{2}, \mathrm{SO}_{2}$, and $\mathrm{C}_{2} \mathrm{H}_{2}$ ), inert atomic Xe gas usually shows weak host-guest or guest-guest interactions during the adsorption process, making the achievement of dense packing of Xe inside the pores more difficult and challenging. Therefore, such dense packing strategy has not been realized yet for $\mathrm{Xe} / \mathrm{Kr}$ separation. 
To achieve the desired dense packing of Xe within porous materials, an ideal material would have an appropriate pore system that densely and orderly arranges a large number of strong binding sites (e.g., polar groups or open metal centers) combined with an optimal pore size close to the kinetic diameter of Xe. We target this matter herein in an ultra-microporous alkyl Cu-based MOF-11 (also called ATC-Cu) ${ }^{13,24}$ that achieves the dense packing of Xe molecules for benchmark Xe capture and separation. We discovered that MOF-11 features small pore channels with suitable pore dimensions (4.4 $\AA$ ) close to the kinetic diameter of Xe atom $(4.047$ $\AA ̊$ ), in which a large number of oppositely adjacent open $\mathrm{Cu}$-metal sites and alkyl cavities are densely arranged along the channels in staggered mode to provide dense and strong adsorption sites for Xe capture (Fig. 1). Single-crystal X-ray diffraction studies on Xe loaded MOF-11 crystals (Xe@MOF-11) identified that this unique pore system can not only introduce the strong Xe-framework interactions, but also enable the dense packing of Xe atoms within the pores due to the efficient $\mathrm{Xe} \cdots$ Xe interactions. MOF-11 thereby exhibits the highest Xe storage density of $2826 \mathrm{~g} \mathrm{~L}^{-1}$ at 1 bar and $298 \mathrm{~K}$, the record-high Xe uptake of $4.0 \mathrm{mmol} \mathrm{g}^{-1}$ at 0.2 bar and $298 \mathrm{~K}$, and very high $\mathrm{Xe} / \mathrm{Kr}$ selectivity of 19.1 among all the reported materials at the same conditions. Dynamic breakthrough experiments confirm the benchmark separation performance of MOF-11 on $\mathrm{Xe} / \mathrm{Kr}$ (20/80) gas mixtures, affording both the unprecedentedly high Xe adsorption capacity $\left(3.46 \mathrm{mmol} \mathrm{g}^{-1}\right)$ and $\mathrm{Kr}$ productivity $\left(350 \mathrm{~cm}^{3} \mathrm{~g}^{-1}\right)$.

\section{RESULTS}

Synthesis and characterisation. The MOF-11 crystal sample was simply prepared from the hydrothermal reaction of $\mathrm{H}_{4} \mathrm{ATC}$ (1,3,5,7-adamantane tetracarboxylic acid) and copper nitrate trihydrate $\left[\mathrm{Cu}\left(\mathrm{NO}_{3}\right)_{2} \cdot 3 \mathrm{H}_{2} \mathrm{O}\right]$ according to the previous literatures with slight modification ${ }^{13,24}$. 
The phase purity of bulk MOF-11 sample was confirmed by matching the experimental and simulated powder X-ray diffraction patterns (PXRD; Supplementary Fig. 2). The dehydrated crystal structure of MOF-11 is depicted in Fig. 1. The framework of MOF-11 consists of paddle-wheel dinuclear $\mathrm{Cu}_{2}(\mathrm{COO})_{4}$ secondary building units (SBUs) linked by the $\mathrm{ATC}^{4-}$ organic linkers to form three-dimensional (3D) network, in which each ATC ${ }^{4-}$ ligand binds with four SBUs and one SBU is bridged by four ATC linkers (Fig. 1a). As a result, MOF-11 exhibits a $(4,4)$-connected PtS structure topology (Supplementary Fig. 1). As depicted in Fig. 1b and 1c, MOF-11 possesses two types of pore channels: one square-shaped pore channel with a diameter of $4.4 \AA$ along the $c$ axis, and one rhombic channel with a diameter of $4.4 \times 5.4 \AA$ (after subtracting van der Waals radius) along the $a$ and $b$ axis. Both of pore channels are constructed by four SBUs and four ATC ${ }^{4-}$ linkers to connect with each other. Most importantly, we found that two $\mathrm{Cu}$-paddlewheel units are oppositely adjacent to each other along two pore channels. The $\mathrm{Cu}-\mathrm{Cu}$ distance between neighboring open copper(II) centers is only $4.4 \AA$ after subtracting van der Waals radius, thereby providing a considerable dual Coulombic interaction within the pores and potentially offering a strong binding site for Xe (Fig. 1b). In addition, there exist two kinds of aliphatic hydrocarbon cavities (cavity II and cavity III) constructed by four enclosed ATC linkers, as shown in Fig.1b and 1c. Eight or twelve hydrogen atoms originated from four ATC linkers point toward the center of the aliphatic hydrocarbon cavities. The average distance between these hydrogen atoms and center of the cavity is only $3.7 \AA$ and $3.5 \AA$, respectively, which provide potential adsorption sites for Xe capture. Most importantly, 
(a)

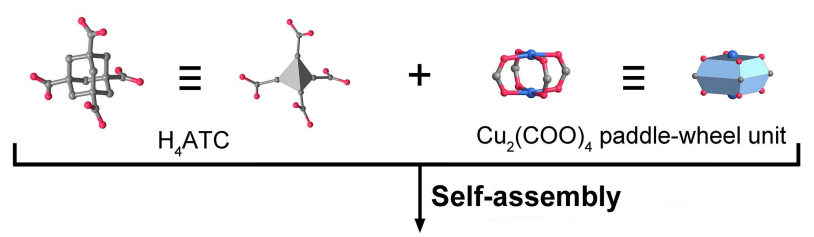

(b)

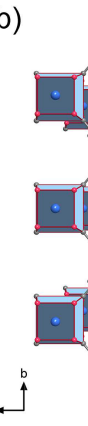

(d) ín

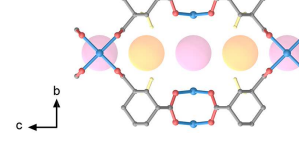

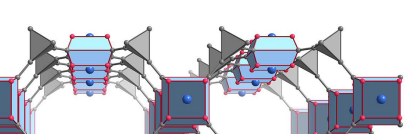

1.0

.

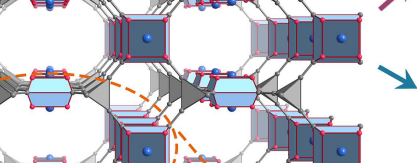

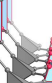

MOF-11

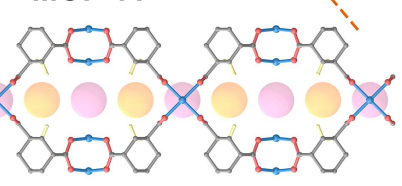

(c)

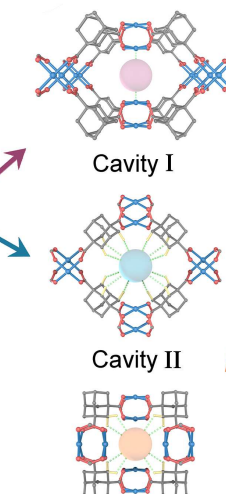

Cavity III (c)

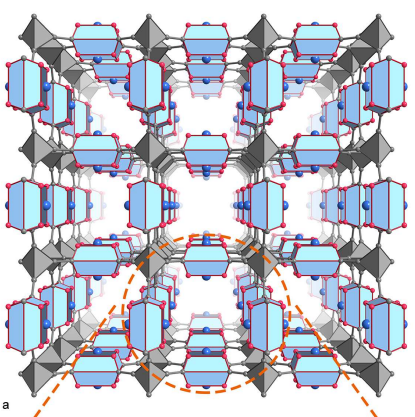

$(\mathrm{e})^{\prime}$

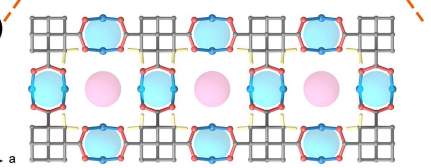

Fig. 1 Crystal structure of MOF-11. a The ATC ${ }^{4-}$ linker and $\mathrm{Cu}_{2}(\mathrm{COO})_{4}$ paddle-wheel building unit. $\mathbf{b}$ and $\mathbf{c}$ Two kinds of pore channels view along with $a$ or $c$ axis, in which three types of pore cavities are around the pore channels. d Cavity I and Cavity III are staggered with each other along the $c$ axis. e Cavity I and Cavity II are staggered with each other along the $a$ and $b$ axis.

cavity I and cavity III show a staggered arrangement inside the pore channel along the $c$ axis.

These staggered arrangement features of oppositely adjacent open metal sites and aliphatic hydrocarbon cavities has the great potential to not only afford the ultrahigh Xe binding affinity but also enable the dense packing of Xe molecules within the pore channels, thus affording concurrently high Xe adsorption and selectivity. The permanent porosity of activated MOF-11 sample was confirmed by nitrogen $\left(\mathrm{N}_{2}\right)$ adsorption isotherms at $77 \mathrm{~K}$. MOF-11 exhibits a typical type-I adsorption behavior with a $\mathrm{N}_{2}$ uptake of $144 \mathrm{~cm}^{3} \mathrm{~g}^{-1}$, implying its microporous nature (Supplementary Fig. 4). The Brunauer-Emmett-Teller (BET) surface area and pore volume of activated MOF-11 samples are evaluated to be $602.8 \mathrm{~m}^{2} \mathrm{~g}^{-1}$ and $0.23 \mathrm{~cm}^{3} \mathrm{~g}^{-1}$ respectively, which are comparable to the values reported in the previous literatures ${ }^{24}$. 
Gas adsorption measurements. The appropriate pore structure with dense binding sites and close pore size $(\sim 4.4 \AA)$ with the diameter of Xe atom encouraged us to investigate the Xe and

$144 \mathrm{Kr}$ adsorption performance of MOF-11. Single-component $\mathrm{Xe}, \mathrm{Kr}, \mathrm{Ar}, \mathrm{N}_{2}$ and $\mathrm{O}_{2}$ sorption isotherms for activated MOF-11 were measured at different temperatures. As shown in Fig. 2a, MOF-11 displays extremely steep variable temperature adsorption isotherms at very low pressure, and almost saturation at around 0.2 bar and $298 \mathrm{~K}$, indicating its strong affinity for Xe molecule. The total Xe uptake at $298 \mathrm{~K}$ and 1 bar can reach up to $4.95 \mathrm{mmol} \mathrm{g}^{-1}$, which is notably higher than most of porous materials such as Ag-MOF-303 (3.25 mmol g-1 $)^{37}, \mathrm{CC} 3$ $\left(2.44 \mathrm{mmol} \mathrm{g}^{-1}\right)^{53}, \mathrm{SBMOF}-1\left(1.4 \mathrm{mmol} \mathrm{g}^{-1}\right)^{31}$, and Co-squarate $\left(1.34 \mathrm{mmol} \mathrm{g}^{-1}\right)^{32}$. At $0.2 \mathrm{bar}$, which is an indicator of the Xe capture ability of adsorbents from a 20/80 $\mathrm{Xe} / \mathrm{Kr}$ mixture, MOF11 exhibits a record high Xe uptake of $4.0 \mathrm{mmol} \mathrm{g}^{-1}$ at $298 \mathrm{~K}$, significantly higher than all the reported benchmark materials including MOF-74-Co $\left(2.57 \mathrm{mmol} \mathrm{g}^{-1}\right)^{42}$, Ag-MOF-303 (2.06 mmol g$\left.)^{-1}\right)^{37}$ SBMOF-1 $\left(1.27 \mathrm{mmol} \mathrm{g}^{-1}\right)^{31}$ and Co-squarate $\left(1.18 \mathrm{mmol} \mathrm{g}^{-1}\right)^{32}$, setting a new benchmark for Xe capture uptake at 0.2 bar. Considering the relatively low BET surface areas 156 density of gaseous Xe (5.89 $\mathrm{g} \mathrm{L}^{-1}$ at 1 bar and 273K) and just slightly lower than the liquid Xe density (3058 $\mathrm{g} \mathrm{L}^{-1}$ at 1 bar and $\left.165 \mathrm{~K}\right)$. To the best of our knowledge, this value is the highest indicating the most highly efficient packing of Xe molecules inside the pores of MOF-11 (Fig. 

can be partially explained by the experimental isosteric heat of adsorption $\left(Q_{\mathrm{st}}\right)$, calculated based on adsorption isotherms at different temperatures. As shown in Fig. 2d, Supplementary Fig. 12, 16 and 17, the initial $Q_{\text {st }}$ value of $\mathrm{Xe}\left(29.4 \mathrm{~kJ} \mathrm{~mol}^{-1}\right)$ is much higher than that of $\mathrm{Kr}$ $\left(23.5 \mathrm{~kJ} \mathrm{~mol}^{-1}\right), \operatorname{Ar}\left(13.9 \mathrm{~kJ} \mathrm{~mol}^{-1}\right), \mathrm{N}_{2}\left(18.4 \mathrm{~kJ} \mathrm{~mol}^{-1}\right)$ and $\mathrm{O}_{2}\left(11.9 \mathrm{~kJ} \mathrm{~mol}^{-1}\right)$, indicating a much stronger binding affinity of Xe. With the increase of Xe loading, the $Q_{\mathrm{st}}$ value can be gradually increased to $34.9 \mathrm{~kJ} \mathrm{~mol}^{-1}$ for Xe. This implies that the Xe adsorption process at high loadings benefits from intermolecular interactions among the adsorbates ${ }^{22}$, probably leading to the efficient packing of Xe molecules inside the pores. Such similar $Q_{\text {st }}$ increase on gas adsorption was also observed in SIFSIX-1-Cu ${ }^{14}$ and CAU-10- $\mathrm{H}^{22}$, which has been proved to show the efficient packing of gas molecules to form gas clusters. Owing to the efficient packing of Xe,
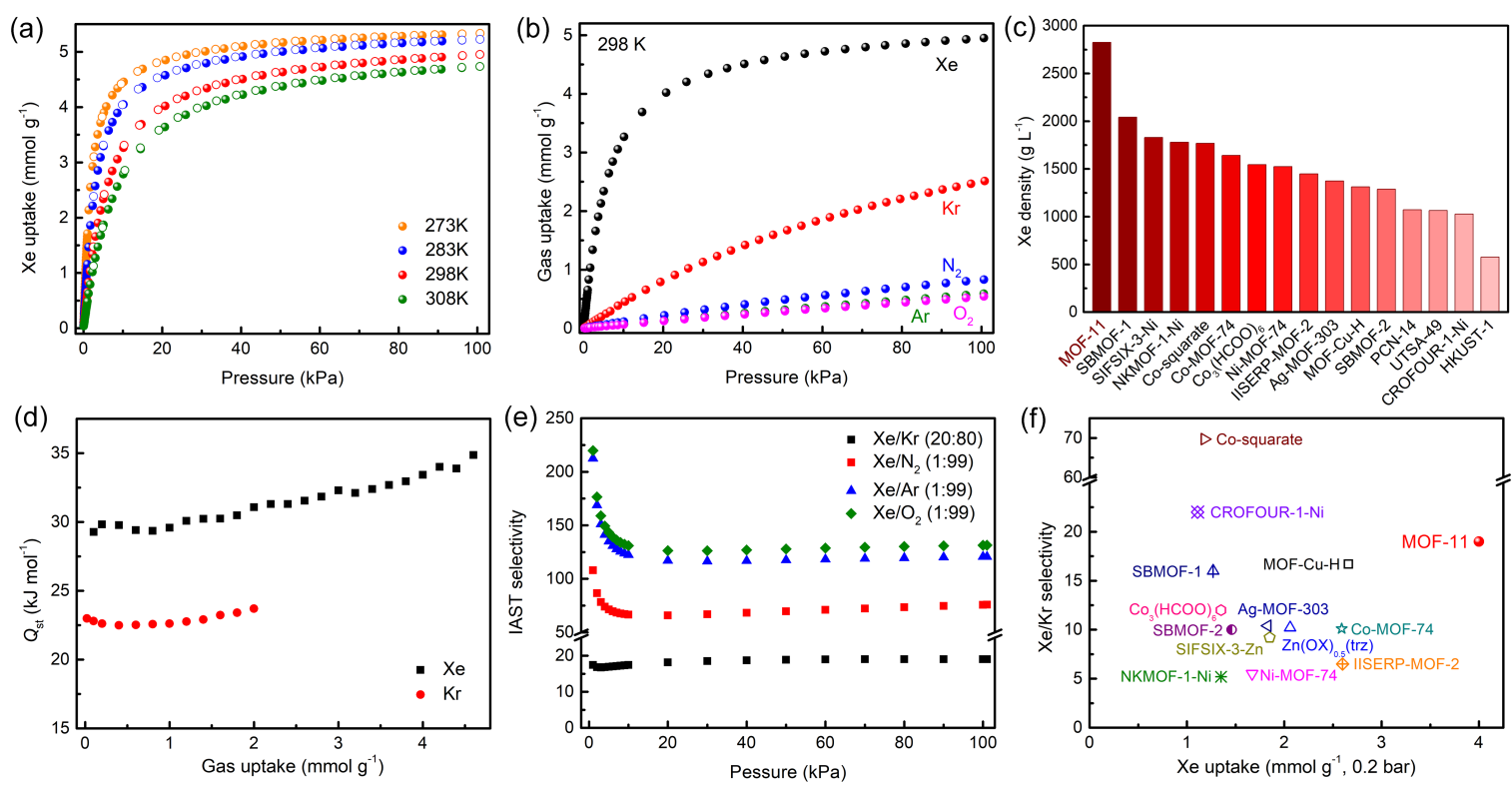
Fig. 2 Experimental characterization of Xe and Kr adsorption in MOF-11. a Xe sorption isotherms of MOF11 at different temperatures. Filled and open circles represent adsorption and desorption data. b Xe, $\mathrm{Kr}, \mathrm{Ar}, \mathrm{N}_{2}$ and $\mathrm{O}_{2}$ adsorption isotherms of MOF-11 at $298 \mathrm{~K}$. $\mathbf{c}$ Comparison of Xe storage density at 1 bar and $298 \mathrm{~K}$ for MOF-11 and other top-performing MOFs. d Isosteric heat of adsorption $\left(Q_{\mathrm{st}}\right)$ for Xe and $\mathrm{Kr}$ of MOF-11. e Calculated IAST selectivity of MOF-11 for $\mathrm{Xe} / \mathrm{Kr}$ (20/80, v/v), $\mathrm{Xe} / \mathrm{N}_{2}(1 / 99), \mathrm{Xe} / \mathrm{O}_{2}(1 / 99)$ and $\mathrm{Xe} / \mathrm{Ar}(1 / 99)$ at 298 K. f Comparison of Xe uptake at 0.2 bar and $298 \mathrm{~K}$ and IAST selectivity of MOF-11 and other top-performing materials. adsorbed solution theory (IAST) based on the experimental gas adsorption isotherms. As shown in Fig. 2e, MOF-11 exhibits a significantly high Xe/Kr selectivity of $\sim 19.1$ at $298 \mathrm{~K}$ and 1 bar, which is comparable to that of the best-performing CROFOUR-1-Ni (22) ${ }^{29}$ and SBMOF$1(16)^{31}$, but higher than Ag-MOF-303 (10.4) $)^{37}$ and MOF-74-Co $(11.8)^{42}$. For 20/80 Xe/Kr separation, high Xe uptake capacity is also very important to determine the final separation performance. In this regard, MOF-11 exhibits a record high Xe adsorption capacity of $4.0 \mathrm{mmol}$ $\mathrm{g}^{-1}$ at $298 \mathrm{~K}$ and 0.2 bar, much higher than that of all the reported porous materials including MOF-74-Co $(2.57 \text { mmol g-1 })^{42}$, Ag-MOF-303 (2.06 mmol g $\left.{ }^{-1}\right)^{37}$, SBMOF-1 $\left(1.27 \mathrm{mmol} \mathrm{g}^{-1}\right)^{31}$ and Co-squarate $\left(1.18 \mathrm{mmol} \mathrm{g}^{-1}\right)^{32}$. As shown in Fig. 2f, we present a comprehensive comparison of MOF-11 with the top-performing MOFs in light of 0.2 bar Xe uptake and Xe/Kr selectivity as concurrent objectives. Most of MOF materials show both lower Xe uptake capacity and $\mathrm{Xe} / \mathrm{Kr}$ selectivity than those of MOF-11. While Co-squarate ${ }^{32}$ and CROFOUR-1$\mathrm{Ni}^{29}$ exhibit higher $\mathrm{Xe} / \mathrm{Kr}$ selectivity than MOF-11, they show extremely lower Xe uptakes at 0.2 bar due to their low pore volumes. Evidently, MOF-11 achieves the benchmark balance with simultaneously high Xe uptake and $\mathrm{Xe} / \mathrm{Kr}$ selectivity among all the reported MOFs so far. To evaluate the intrinsic interaction between adsorbents and adsorbed gas at very low pressure, 
the Xe Henry coefficient for MOF-11 is calculated based on Xe adsorption isotherms at low pressure range $(0-5 \mathrm{kPa})$ and $298 \mathrm{~K}$. MOF-11 displays the second largest Henry coefficient value of $69.5 \mathrm{mmol} \mathrm{g}^{-1} \mathrm{bar}^{-1}$ for Xe and a high thermodynamic Xe/Kr selectivity of 15.9 among all the reported top-performing MOFs ${ }^{26}$. This indicates that MOF-11 is also placed among the most promising candidates for Xe capture and separation under dilute conditions. In addition, MOF-11 also exhibits an ultrahigh selectivity for 1/99 Xe/Ar (120), Xe/ $\mathrm{N}_{2}$ (76), or Xe/O $\mathrm{O}_{2}(131)$ binary gas mixtures (Fig. 2e), respectively.

Single-crystal diffraction studies on Xe-loaded MOF-11. To gain better insight into the record-high Xe storage density and capture capacity observed in MOF-11, we performed single-crystal X-ray diffraction (SCXRD) measurements on activated MOF-11 crystals filled with Xe. After the as-synthesized MOF-11 crystals in the capillary glass tube were activated at $150{ }^{\circ} \mathrm{C}$ under vacuum, the capillary glass tube was filled by pure Xe gas to 1 bar at $298 \mathrm{~K}$ and sealed. Single-crystal X-ray diffraction data collected at room temperature revealed the crystal structure of Xe@MOF-11 with a formula of $\mathrm{Cu}_{2}\left(\mathrm{C}_{14} \mathrm{H}_{12} \mathrm{O}_{8}\right) \mathrm{Xe}_{3}$. As shown in Fig. 3, MOF-11 was found to exhibit three binding sites (site-1, site-2 and site-3) for Xe molecules. Fig. 3a shows that Xe atom is located in the middle of the two oppositely $\mathrm{Cu}$-paddle wheels (site-1), which dually interacts with the two metal sites with a short $\mathrm{Xe}{ }^{\cdots} \mathrm{Cu}$ distance of $2.950 \AA$. This value is much shorter than the metal-Xe interaction distance found in MOF-74-Co (Xe $\cdots \mathrm{Co}$, 3.22(3) $\AA)^{42}$ and MOF-74-Ni $(\mathrm{Xe} \cdots \mathrm{Ni}, 3.17(4) \AA)^{42}$, indicating a much stronger Xe binding affinity of MOF-11. The Xe binding site- 2 is located in the center of eight $\mathrm{H}$ atoms from four ATC linkers in rectangular channels with a Xe $\cdots \mathrm{H}$ distances of $3.678 \AA$ (Fig. 3b). As depicted in Fig. 3c, the Xe binding site-3 is in the center of aliphatic hydrocarbon cavity of rhombic 
226 linkers with the $\mathrm{Xe} \cdots \mathrm{H}$ distances range from $3.477 \AA$ to $3.988 \AA$. Due to the staggered 227 arrangement of site- 1 and site- 2 along the $a$ and $b$ axis, the adsorbed Xe atom in site- 2 interacts 228 with two adjacent Xe atoms in site-1 with a Xe1 $\cdots$ Xe2 distance of $4.221 \AA$ along the $a$ or $b$ axis (Fig. 3d). In addition, Xe atom in site-3 also strongly interacts with Xe atom in site-I with

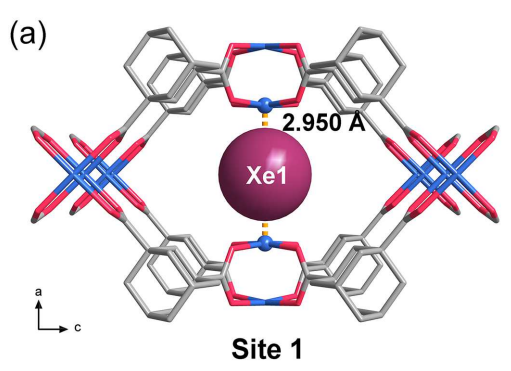

(a)

Site 1 (b)

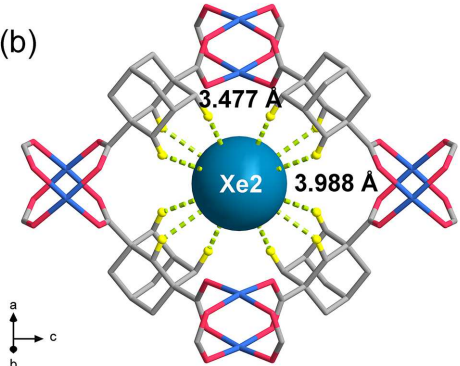

Site 2

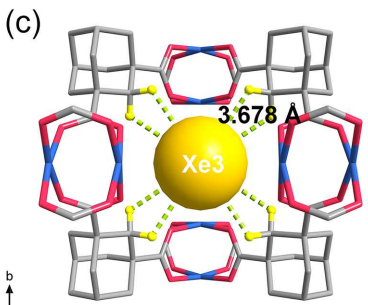

Site 3

(d)
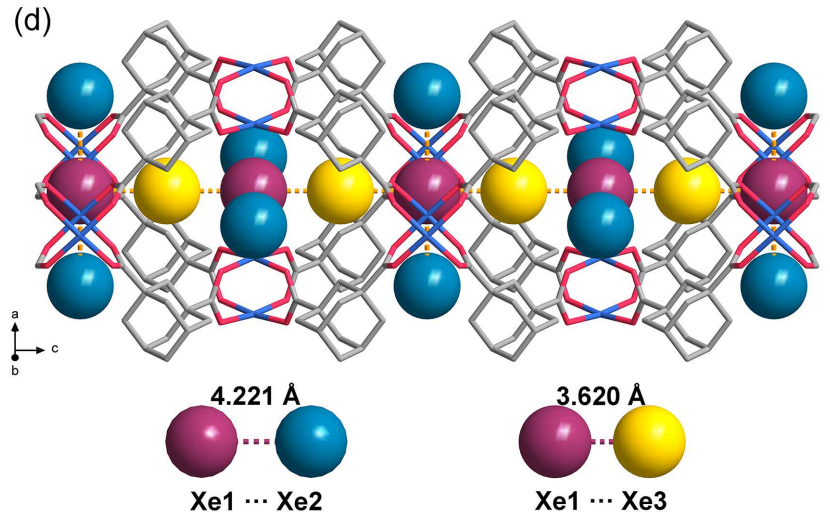

(e)

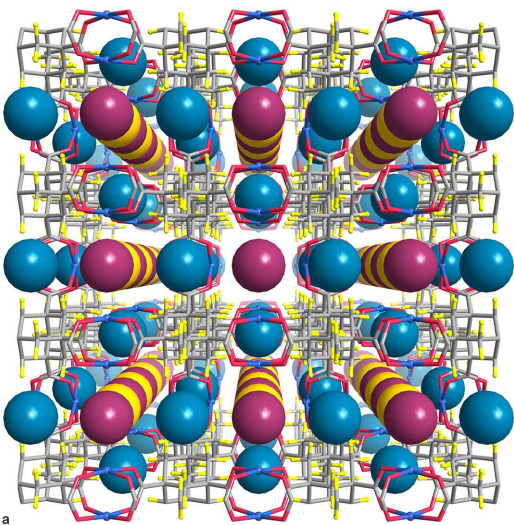

230

Fig. 3 Illustration of the adsorbed Xe atoms in MOF-11 as determined by single-crystal X-ray diffraction.

a The Xe binding site-1 (Xe1) located in the center of the two adjacent open Cu-metal sites from oppositely $\mathrm{Cu}_{2}(\mathrm{COO})_{4}$ paddle-wheels with a $\mathrm{Xe}{ }^{\cdots} \mathrm{Cu}$ distance of $2.950 \AA$. b The Xe binding site-2 (Xe2) in the aliphatic hydrocarbon cavity II. $\mathbf{c}$ The Xe binding site-3 (Xe3) in the aliphatic hydrocarbon cavity III. $\mathbf{d}$ The intermolecular interactions between Xe1 and Xe2 with the dense packing of Xe molecules along the $a$ or $b$ axis, and the intermolecular interactions between $\mathrm{Xe} 1$ and $\mathrm{Xe} 3$ with the dense packing of Xe molecules along the $c$ axis. e The dense packing of Xe in the whole pore structure of MOF-11, viewed along the $c$ axis.

a Xe $3 \cdots$ Xe1 distance of $3.620 \AA$, affording the staggered packing of Xe along the $c$ axis (Fig.

3d). It should be noted that the observed $\mathrm{Xe} \cdots \mathrm{Xe}$ contact distance between site- 1 and site- 3 
240 (3.620 $\AA)$ are notably shorter than that found in the Xe-loaded crystal structures of 241 Xe@SBMOF-1 (5.567 A $)^{31}$, Xe@SBMOF-2 $(5.181 \AA)^{45}$, Xe@MOF-74-Co $(4.42 \AA)^{42}$ and 242 Xe@MOF-74-Ni $(\sim 4.50 \AA)^{42}$ collected at 200K. This distance is even much shorter than the $243 \mathrm{Xe} \cdots \mathrm{Xe}$ distance in the crystal structure of pure Xe gas $(\sim 4.34 \AA)$ collected at $26 \mathrm{~K}$, as well 244 as the van der Waals diameter of Xe atom $(4.32 \AA)^{54}$. Evidently, the suitable pore architecture 245 of MOF-11 enables the unprecedentedly dense packing of Xe molecules within the pore 246 channels (Fig. 3e), thus accounting for the record-high Xe adsorption capacity and storage 247 density observed in MOF-11. The SCXRD data indicates that the adsorbed Xe amount in site248 1, site-2 and site-3 corresponds to $2.2,2.2$ and $2.2 \mathrm{mmol} \mathrm{g}^{-1}$ gas uptake, wherein the total value 249 of $6.6 \mathrm{mmol} \mathrm{g}^{-1}$ is very close to the experimentally Xe uptake $\left(5.28 \mathrm{mmol} \mathrm{g}^{-1}\right)$ at $273 \mathrm{~K}$ and 1 250 bar.

251 Column breakthrough experiments. To verify the practical applicability of MOF-11 for $252 \mathrm{Xe} / \mathrm{Kr}$ separation, dynamic breakthrough experiments were carried out on the column packed 253 with activated MOF-11 at $298 \mathrm{~K}$ for a representative $\mathrm{Xe} / \mathrm{Kr}(20 / 80)$ gas mixture that mimics the feedstock generated from cryogenic process in air separation. As shown in Fig. 4a, a very 255 clean $\mathrm{Xe} / \mathrm{Kr}$ separation was accomplished by MOF-11. Pure $\mathrm{Kr}$ broke through immediately at $256 \sim 28 \mathrm{~min}^{-1}$ for MOF-11 after the injection of $\mathrm{Xe}-\mathrm{Kr}$ gas mixture into columns, while Xe

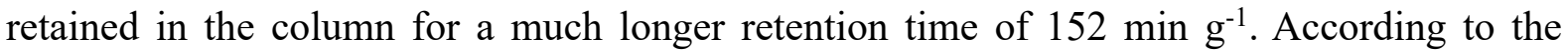
breakthrough curves, the $\mathrm{Xe} / \mathrm{Kr}$ selectivity of MOF-11 was calculated up to 16.6 , which is 

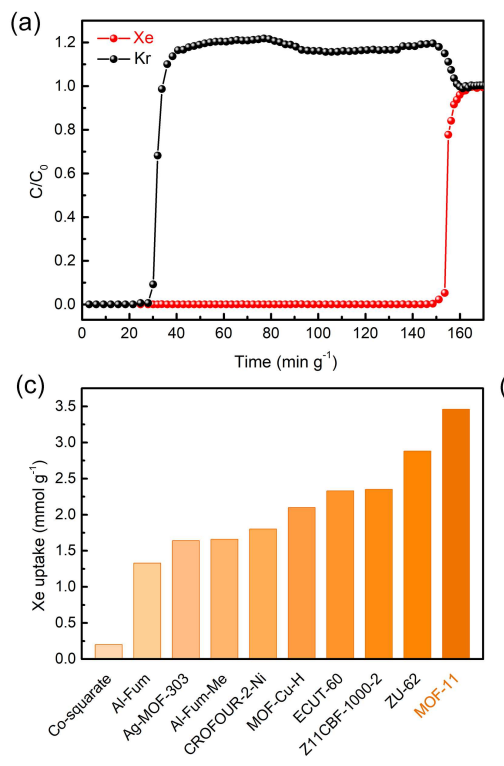
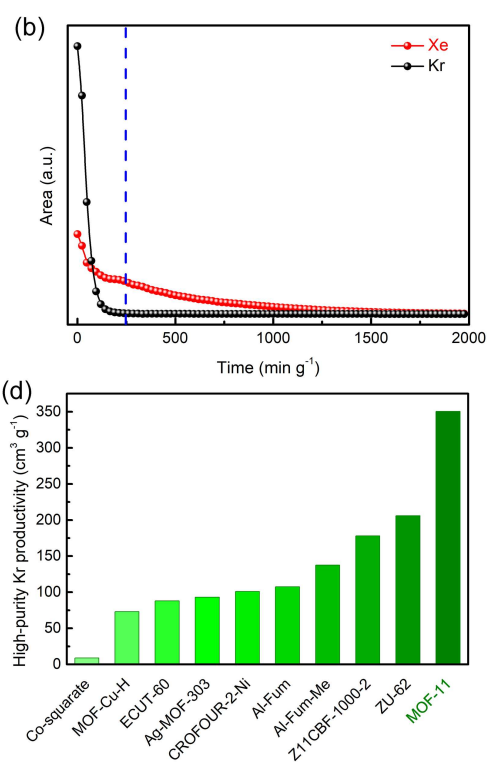

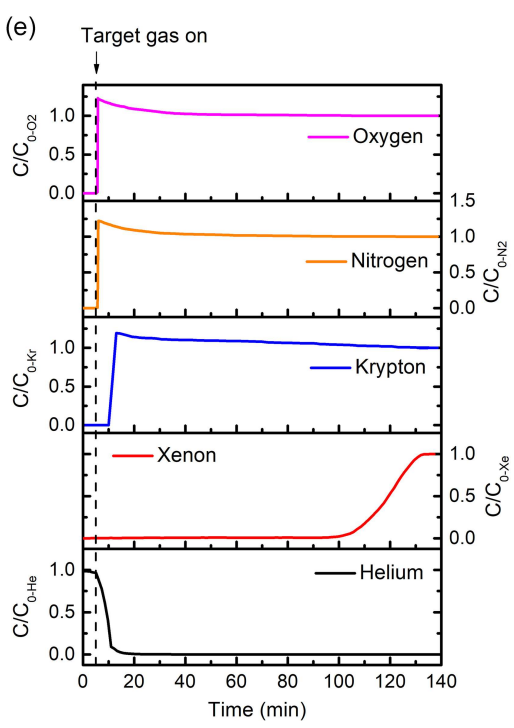

259

Fig. 4 Column breakthrough experiments using MOF-11 at room temperature and 1 bar. a Experimental column breakthrough curves for $\mathrm{Xe} / \mathrm{Kr}$ (20/80) gas mixture adsorbed on MOF-11 at 1 bar and $298 \mathrm{~K}$ under a flow rate of $2.5 \mathrm{~mL} \mathrm{~min}^{-1}$. b The signals of desorbed $\mathrm{Xe}$ and $\mathrm{Kr}$ during the regeneration process under $1.25 \mathrm{~mL} \mathrm{~min}^{-1}$ He flow at $298 \mathrm{~K}$. c Comparison of the amount of Xe capture during the column breakthrough for MOF-11 with other top-performing porous materials at $298 \mathrm{~K}$. d Comparison of high-purity $\mathrm{Kr}$ productivity during the column breakthrough for MOF-11 with other promising porous materials at 298K. e Experiment breakthrough curves of MOF-11 at low concentrations using a gas-mixture (400 ppm Xe and 40 ppm Kr in dry air) at $298 \mathrm{~K}$ under a flow rate of $2.5 \mathrm{~mL} \mathrm{~min}^{-1}$.

higher than the most top-performing MOFs reported such as MOF-Cu-H, Ag-MOF-303 and MOF-74-Co. During this dynamic separation process, MOF-11 exhibits the record high Xe adsorption capacity of $3.46 \mathrm{mmol} \mathrm{g}^{-1}$ and the highest productivity of high-purity $\mathrm{Kr}(>99.9 \%)$ of $350 \mathrm{~cm}^{3} \mathrm{~g}^{-1}$ obtained from the outlet effluent. These values are significantly higher than those of all the reported porous materials so far, including MOF-Cu-H $\left(2.09 \mathrm{mmol} \mathrm{g}^{-1}\right.$ and 73 $\left.\mathrm{cm}^{3} \mathrm{~g}^{-1}\right)^{33}$, Ag-MOF-303 (1.64 mmol g-1 and $\left.93 \mathrm{~cm}^{3} \mathrm{~g}^{-1}\right)^{37}$, CROFOUR-2-Ni (1.91 mmol g-1 and $\left.101 \mathrm{~cm}^{3} \mathrm{~g}^{-1}\right)^{29}$ and ZJU-62 $\left(2.88 \mathrm{mmol} \mathrm{g}^{-1} \text { and } 206 \mathrm{~cm}^{3} \mathrm{~g}^{-1} \text { at } 273 \mathrm{~K}\right)^{28}$. MOF-11 can be easily regenerated by vacuum or purging with helium for around $60 \mathrm{~min}$ at $298 \mathrm{~K}$ due to its 
relatively low $Q_{\text {st }}$ value of $\mathrm{Xe}$ and $\operatorname{Kr}\left(29.4 \mathrm{~kJ} \mathrm{~mol}^{-1}\right.$ and $\left.23.5 \mathrm{~kJ} \mathrm{~mol}^{-1}\right)$. During the desorption

277 process, high-purity Xe (99\%) could be produced with a high productivity of $66.8 \mathrm{~cm}^{3} \mathrm{~cm}^{-3}$ (a

278 recovery rate of $\sim 61.5 \%$ for all the desorbed Xe). Multiple breakthrough tests for $\mathrm{Xe} / \mathrm{Kr}$ 279 mixtures confirmed that MOF-11 maintains the excellent Xe adsorption capacity and separation performance within three continuous cycles, indicating its good recyclability for $\mathrm{Xe} / \mathrm{Kr}$ separation (Supplementary Fig. 19).

To evaluate the performance of MOF-11 on capture and separation of $\mathrm{Xe}$ and $\mathrm{Kr}$ from the off-gases in UNF reprocessing, we further carried out the breakthrough experiments using a low Xe-Kr concentration gas mixture (400 ppm Xe, 40 ppm Kr balanced with dry air). After initially purging with $\mathrm{He}$ for $5 \mathrm{~min}$, the target gas mixture was injected into the column. As shown in Fig. 4e, $\mathrm{N}_{2}, \mathrm{O}_{2}$ and $\mathrm{Kr}$ broke through almost immediately after the gas-mixture injection. While Xe was retained much longer in the column with a retention time of about 100 min, in comparison with $\mathrm{N}_{2}, \mathrm{O}_{2}$ and $\mathrm{Kr}$, suggesting the high performance of MOF-11 on Xe capture and $\mathrm{Xe} / \mathrm{Kr}$ separation at dynamic dilute condition. Under these dilute conditions, the Xe adsorption capacity of MOF-11 was calculated to be $24.5 \mathrm{mmol} \mathrm{kg}^{-1}$ at $298 \mathrm{~K}$. This value is extremely higher than that of all the benchmark materials reported so far, such as SBMOF$\left(13.0 \mathrm{mmol} \mathrm{kg}{ }^{-1}\right)^{33}$. These results prove the best separation performance of MOF-11 for both

$294 \mathrm{Xe} / \mathrm{Kr}$ separation from $\mathrm{Xe} / \mathrm{Kr}$ binary gas mixture and Xe capture from off-gas mixture under UNF reprocessing conditions. 
297 In summary, we have realized an ultra-microporous MOF (MOF-11) with dense packing of Xe 298 inside the pores for highly efficient Xe capture and separation. The Xe loaded SCXRD studies 299 identified that the dense and staggered arrangement of the oppositely adjacent open $\mathrm{Cu}^{2+}$-metal 300 sites and alkyl cavities along the small channels can not only provide strong binding affinity with Xe but also enable the dense packing of Xe inside the pores, thus simultaneously optimizing the $\mathrm{Xe}$ adsorption uptake and $\mathrm{Xe} / \mathrm{Kr}$ selectivity. This material thereby achieves the highest Xe storage density at ambient conditions, record-high Xe adsorption capacity at 0.2 bar and $298 \mathrm{~K}$ and concurrently high $\mathrm{Xe} / \mathrm{Kr}$ selectivity reported so far. The breakthrough experiments affirmed that MOF-11 can efficiently separate $\mathrm{Kr}$ from $\mathrm{Xe} / \mathrm{Kr}(20 / 80)$ mixtures with both the highest Xe uptake capacity and $\mathrm{Kr}$ productivity, making it as a new benchmark material for highly efficient $\mathrm{Xe} / \mathrm{Kr}$ separation. This work may provide a new strategy of designing porous MOFs with dense packing of Xe inside the pores to achieve excellent $\mathrm{Xe} / \mathrm{Kr}$ separation performance.

\section{Methods}

Synthesis of MOF-11. The MOF-11 crystal sample was simply prepared according to the previously reported literature with slight modification. ${ }^{13,24} \mathrm{H}_{4} \mathrm{ATC}(0.070 \mathrm{~g}, 0.22 \mathrm{mmol})$ and $\mathrm{Cu}\left(\mathrm{NO}_{3}\right)_{2} \cdot 3 \mathrm{H}_{2} \mathrm{O}$ $(0.532 \mathrm{~g}, 0.47 \mathrm{mmol})$ were dissolved in the aqueous $\mathrm{NaOH}$ solution $(15 \mathrm{M}, 15 \mathrm{~mL})$. The reactants were added into a Teflon-lined autoclave and heated at $573 \mathrm{~K}$ for 18 hours. The green crystals of MOF-11 were obtained at the bottom of the vial. The as-synthesized samples were filtrated and washed with methanol, and then exchanged with methanol for 2 days prior to activation. 

to obtain the powder X-ray diffraction (PXRD) patterns $\left(2 \Theta=5 \sim 50^{\circ}\right)$. Thermogarvimeteric analysis

320 (TGA) was performed on a TGA-550 (TA instrument) analyzer under $\mathrm{N}_{2}$ gas flow from $30{ }^{\circ} \mathrm{C}$ to $800{ }^{\circ} \mathrm{C}$

321 in an aluminum crucible with a heating rate of $10{ }^{\circ} \mathrm{C} \min ^{-1}$ using $3 \sim 6 \mathrm{mg}$ of products..

322 Gas adsorption measurements. The gas sorption isotherms were measured using a surface characterization analyzer (Micrometritics 3Flex). The as-synthesized MOF-11 samples were degassed at $150{ }^{\circ} \mathrm{C}$ for 18 hours to yield guest-free phase before sorption measurements. The $\mathrm{N}_{2}$ sorption isotherms at $77 \mathrm{~K}$ were measured using a liquid nitrogen bath. The gas sorption isotherms at different temperatures were collected using a Micromeritics's ISO Controller (Thermoelectric Cooled Dewar) to maintain the temperatures.

Single-crystal diffraction and structure determination. A single crystal of MOF-11 was selected and putted into a capillary glass tube with a $0.1 \mathrm{~mm}$ inner diameter. This capillary glass tube was activated at $150{ }^{\circ} \mathrm{C}$ under vacuum for 24 hours. And then the capillary glass tube was filled by pure Xe gas up to 1 bar at $298 \mathrm{~K}$ and then sealed. The single-crystal data on the Xe-loaded activated MOF-11 crystal were collected using an Agilent Supernova CCD diffractometer equipped with graphite-monochromatic enhanced Mo-K $\alpha$ radiation $(\lambda=0.71073 \AA)$ at room temperature. The datasets were corrected by empirical absorption correction using spherical harmonics, implemented in the SCALE3 ABSPACK scaling algorithm. The structure was solved by direct methods and refined by full matrix least-squares methods with the SHELX-97 program package.$^{55}$ The crystal data are summarized in Supplementary Table 4. 

$\mathrm{mg}$ ) was packed into a steel column (the steel column is about $12 \mathrm{~cm}$ long with a 4-mm inner and 6.4$\mathrm{mm}$ outer diameter) with silica wool filling the void space. The column was activated by heating at 423

$342 \mathrm{~K}$ under vacuum for $12 \mathrm{~h}$ and then purged by helium gas with a flow rate of $\left(2.5 \mathrm{~mL} \mathrm{~min}^{-1}\right)$ for $2 \mathrm{~h}$ before the column temperature was decreased to $298 \mathrm{~K}$. A circulator bath was used to maintain the columns at $298 \mathrm{~K}$. The flow of helium gas was stopped while target gas mixtures (a 20/80 Xe/Kr binary gas mixture or 400 ppmv $\mathrm{Xe} 40 \mathrm{ppmv}, \mathrm{Kr}$ balanced with dry air) were fed to the column with a flow rate of $2.5 \mathrm{~mL} \mathrm{~min}^{-1}$. The flow of helium and targeted gas mixture was controlled by two mass flow controllers. The downstream was monitored by a Hiden mass spectrometer (HPR 20). The desorption test of MOF-11 was carried out using the same dynamic gas breakthrough equipment, while the downstream was monitored by a gas chromatography (SCION GC-450) with thermal conductivity detector (TCD, detection limit $0.1 \mathrm{ppm}$ ). The standard gases were used to calibrate the concentration of the outlet gas. After the breakthrough tests, MOF-11 samples in the steel column can be readily generated by sweeping $\mathrm{He}$ gas $\left(10 \mathrm{~mL} \mathrm{~min}^{-1}\right)$ at room temperature for $40 \mathrm{~min}$ or in high vacuum at room temperature for $60 \mathrm{~min}$.

The adsorption capacity was estimated from the breakthrough curves using the following equation:

$n_{\mathrm{ads}}=F C_{\mathrm{i}} t_{\mathrm{i}}$

Where $n_{\text {ads }}$ is the adsorption capacity of the gas i, $F$ is the total molar flow, $C_{\mathrm{i}}$ is the concentration of the breakthrough profile.

The selectivity was then calculated according to the equation:

360

$$
\mathrm{S}_{\mathrm{A} / \mathrm{B}}=\frac{X_{\mathrm{A}} / X_{\mathrm{A}}}{Y_{\mathrm{A}} / Y_{\mathrm{B}}}
$$



the mole fractions of the gases $\mathrm{A}$ and $\mathrm{B}$ in the bulk phase.

\section{Data availability}

All data involved in this work are included in this article and the corresponding supplementary information. Additional graphics, TG curves, PXRD diffractograms, multiple cycle breakthrough experiments, dual site Langmuir-freundlich isotherm model fitting, isosteric heat of adsorption calculations, IAST calculations of adsorption selectivities and column breakthrough test setup are available as Supplementary Information. The crystal structure data of Xe-loaded MOF-11 have been deposited at CCDC under the deposition numbers CCDC: 2130314 . These data can be obtained free of charge from the CCDC database via www.ccdc.cam.ac.uk.

\section{References}

1. Lane G. A. et al. Anesthetics as teratogens: nitrous oxide is fetotoxic, xenon is not. Science 210, 899-

2. Kerry, F. G. Industrial Gas Handbook: Gas Separation and Purification (CRC Press, 2007).

3. Nandanwar, S. U. et al. Capture of harmful radioactive contaminants from off-gas stream using porous solid sorbents for clean environment-a review. Chem. Eng. J. 306, 369-381 (2016).

4. Jian, L. et al. Metal-organic frameworks for removal of Xe and $\mathrm{Kr}$ from nuclear fuel reprocessing plants. Langmuir 28, 11584-11589 (2012).

5. Fontaine, J. P. et al. Atmospheric xenon radioactive isotope monitoring. J. Environ. Radioact. 72, 129135 (2004).

6. Ying, R. T. Gas separation by adsorption processes (Butterworth-Heinemann, 2013).

7. Yaghi, O. M. et al. Reticular synthesis and the design of new materials. Nature 423, 705-714 (2003). 
9. Peh, S. et al. Scalable and sustainable synthesis of advanced porous materials. ACS Sustainable Chem. Eng. 7, 3647-3670 (2019).

10. Han, X., Yang S., Schröder, M. Porous metal-organic frameworks as emerging sorbents for clean air. Nat. Rev. Chem. 3, 108-118 (2019).

11. Mukherjee, S., Zaworotko, M. J. Crystal engineering of hybrid coordination networks: from form to function. Trends in Chem. 6, 506-518 (2020).

12. Lin, R.-B., Xiang S., Zhou, W., Chen, B. Microporous metal-organic framework materials for gas separation. Chem 6, 337-363 (2020).

13. Chen, B. et al. $\mathrm{Cu}_{2}(\mathrm{ATC}) \cdot 6 \mathrm{H}_{2} \mathrm{O}$ : Design of open metal sites in porous metal-organic crystals (ATC: 1,3,5,7-adamantane tetracarboxylate). J. Am. Chem. Soc. 122, 11559-11560 (2000).

14. Cui, X. et al. Pore chemistry and size control in hybrid porous materials for acetylene capture from ethylene. Science 353, 141-144 (2016).

15. Qazvini, O. T., Babarao, R. Telfer, S. G. Selective capture of carbon dioxide from hydrocarbons using a metal-organic framework. Nat. Commun. 12, 197 (2021).

16. Adil, K. et al. Gas/vapour separation using ultra-microporous metal-organic frameworks: insights into the structure/separation relationship. Chem. Soc. Rev. 46, 3402-3430 (2017).

17. Liao, P.-Q. et al. Efficient purification of ethene by an ethane-trapping metal-organic framework. Nat. Commun. 6, 8697 (2015).

18. Zhang, Z. et al. Perspective of microporous metal-organic frameworks for $\mathrm{CO}_{2}$ capture and separation. Energy Environ. Sci. 7, 2868-2899 (2014).

19. Easun, T. L., Moreau, F., Yan, Y., Yang, S., Schröder, M. Structural and dynamic studies of substrate binding in porous metalorganic frameworks. Chem. Soc. Rev. 46, 239-274 (2017).

20. Zhao, X., Wang, Y., Li, D. S., Bu, X., Feng, P. Metal-organic frameworks for separation. Adv. Mater. 30, 1705189 (2018).

21. Zeng, H., Xie, M.,Wang, T., Wei, R.-J., Xie, X.-J., Zhao, Y., Lu, W., Li, D. Orthogonal-array dynamic molecular sieving of propylene/propane mixtures. Nature 595, 542-548 (2021).

22. Pei, J. et al. Dense packing of acetylene in a stable and low-cost metal-organic framework for efficient $\mathrm{C}_{2} \mathrm{H}_{2} / \mathrm{CO}_{2}$ separation. Angew. Chem. Int. Ed. 60, 25068-25074 (2021).

23. Xiang, S. et al. Microporous metal-organic framework with potential for carbon dioxide capture at ambient conditions. Nat. Commun. 3, 954 (2012). 
24. Niu, Z. et al. A metal-organic framework based methane nano-trap for the capture of coal-mine methane. Angew. Chem. Int. Ed. 58, 10138-10141 (2019).

25. Banerjee, D. et al. Potential of metal-organic frameworks for separation of xenon and krypton. Acc. Chem. Res. 48, 211-219 (2015).

26. Banerjee, D. et al. Xenon gas deparation and storage using metal-organic frameworks, Chem 4, 466-494 (2018).

27. Wang, H., Li, J. General strategies for effective capture and separation of noble gases by metal-organic frameworks. Dalton Trans. 47, 4027-4031 (2018).

28. Wang, Q. et al. Separation of Xe from $\mathrm{Kr}$ with record selectivity and productivity in anion-pillared ultramicroporous materials by inverse size-sieving. Angew. Chem. Int. Ed. 132, 3451-3456 (2020).

29. Mohamed, M. H. et al. Hybrid ultra-microporous materials for selective xenon adsorption and separation, Angew. Chem. Int. Ed. 55, 8285-8289 (2016).

30. Wang, H. et al. The first example of commensurate adsorption of atomic gas in a MOF and effective separation of xenon from other noble gases. Chem. Sci. 5, 620-624 (2014).

31. Banerjee, D. et al. Metal-organic framework with optimally selective xenon adsorption and separation. Nat. Commun. 7, 11831-11837 (2016).

32. Li, L. et al. A robust squarate-based metal-organic framework demonstrates record-high affinity and selectivity for xenon over krypton. J. Am. Chem. Soc. 141, 9358-9364 (2019).

33. Xiong, S. et al. A microporous metal-organic framework with commensurate adsorption and highly selective separation of xenon. J. Mater. Chem. A 6, 4752-4758 (2018).

34. Thallapally, P. K., Grate, J. W., Motkuri, R. K. Facile xenon capture and release at room temperature using a metal-organic framework: a comparison with activated charcoal. Chem. Commun. 48, 347-349 (2012).

35. Perry, IV, J. et al. Noble gas adsorption in metal-organic frameworks containing open metal sites. J. Phys. Chem. C 118, 11685-11698 (2014).

36. Liu, J., Strachan, D. M., Thallapally, P. K. Enhanced noble gas adsorption in Ag@MOF-74-Ni. Chem. Commun. 50, 466-468 (2014).

37. Wang, $\mathrm{H}$. et al. Docking of $\mathrm{Cu}^{\mathrm{I}}$ and $\mathrm{Ag}^{\mathrm{I}}$ in metal-organic frameworks for adsorption and separation of xenon. Angew. Chem. Int. Ed. 60, 3417-342 (2021). 
38. Lee, S. J. et al. Adsorptive separation of xenon/krypton mixtures using a zirconium-based metal-organic framework with high hydrothermal and radioactive stabilities. J. Hazard. Mater. 320, 513-520 (2016).

39. Lee, S. J. et al. Adsorptive separation of xenon/krypton mixtures using ligand controls in a zirconiumbased metal-organic framework. Chem. Eng. J. 335, 345-351 (2018).

40. Sikora, B. J., Wilmer, C. E., Greenfield, M. L., Snurr, R. Q. Thermodynamic analysis of Xe/Kr selectivity in over 137000 hypothetical metal-organic frameworks. Chem. Sci. 3, 2217-2223 (2012).

41. Simon, C. M. et al. What are the best materials to separate a Xenon/Krypton mixture. Chem. Mater. 27, 4459-4475 (2015).

42. Kapelewski, M. T. et al. Separation of xenon and krypton in the metal-organic frameworks $\mathrm{M}_{2}(m$-dobdc) (M = Co, Ni). Isr. J. Chem. 58, 1138-1143 (2018).

43. Meek, S. T. et al. Effects of polarizability on the adsorption of noble gases at low pressures in monohalogenated isoreticular metal-organic frameworks. J. Phys. Chem. C 116, 19765-19772 (2012).

44. Elsaidi, S. K. et al. Effect of ring rotation upon gas adsorption in SIFSIX-3-M (M = Fe, Ni) pillared square grid networks. Chem. Sci. 8, 2373-2380 (2017).

45. Chen, X. et al. Direct observation of Xe and $\mathrm{Kr}$ adsorption in a Xe-selective microporous metal-organic framework. J. Am. Chem. Soc. 137, 7007-7010 (2015).

46. Liu, B. et al. Enhanced xenon adsorption and separation with an anionic indium-organic framework by ion exchange with $\mathrm{Co}^{2+}$. RSC Adv. 7, 55012-55019 (2017).

47. Yan, Z. et al. Methyl functionalized Zr-Fum MOF with enhanced Xenon adsorption and separation. Sep. Purif. Techol. 239, 116514 (2020).

48. Xiong, S. et al. A flexible zinc tetrazolate framework exhibiting breathing behaviour on xenon adsorption and selective adsorption of xenon over other noble gases. J. Mater. Chem. A 3, 10747-10752 (2015).

49. $\mathrm{Yu}, \mathrm{L}$. et al. Tuning the channel size and structure flexibility of metal-organic frameworks for the selective adsorption of noble gases. Inorg. Chem. 58, 15025-15028 (2019).

50. Yan, Z. et al. Pore size reduction by methyl function in aluminum-based metal-organic frameworks for xenon/krypton separation. Cryst. Growth Des. 20, 8039-8046 (2020).

51. Chakraborty, D. et al. An ultra-microporous metal-organic framework with exceptional Xe capacity. Chem. Eur. J. 26, 12544-12548 (2020).

52. Zhang, H. et al. Robust metal-organic framework with multiple traps for trace Xe/Kr separation. Sci. Bull. 66, 1073-1079 (2021). 


\section{4}

535

536

537

538

539

540

541

\section{Competing interests}

546 The authors declare no competing interests.

\section{Acknowledgements} Foundation of China (92163110 and 52073251).

\section{Author contributions}

53. Chen, L. et al. Separation of rare gases and chiral molecules by selective binding in porous organic cages. Nat. Mater. 13, 954-960 (2014).

54. Sears, D. R., Klug, H. P. Density and expansivity of solid xenon. J. Chem. Phys. 37, 3002 (1962).

55. Sheldrick, G. M. SHELXL-97, Program for the refinement of crystal structures, University of Göttingen, Göttingen, Germany (1997).

We acknowledge the support of the "President Fund" (YZJJLX2019003), "Innovation Fund" (CX2019008) in China Academy of Engineering Physics (CAEP) and the National Natural Science

Y.-L.P. designed the experiments, Q.L. synthesized MOF-11, and performed the activation and singlecomponent gas-adsorption experiments. B. L. and Y. G. performed column breakthrough experiments. H.-M. W. and J. P. performed single-crystal X-ray diffraction studies. Q. L. and H.-M. wrote the original draft of the manuscript; S.X., B.L. and X.W. conceived the project and Review \& Editing the manuscript. 
549 Table of Contents artwork

550

551 Dense Packing of Xenon in an Ultra-Microporous Metal-Organic

552 Framework for Benchmark Xenon Capture and Separation

553

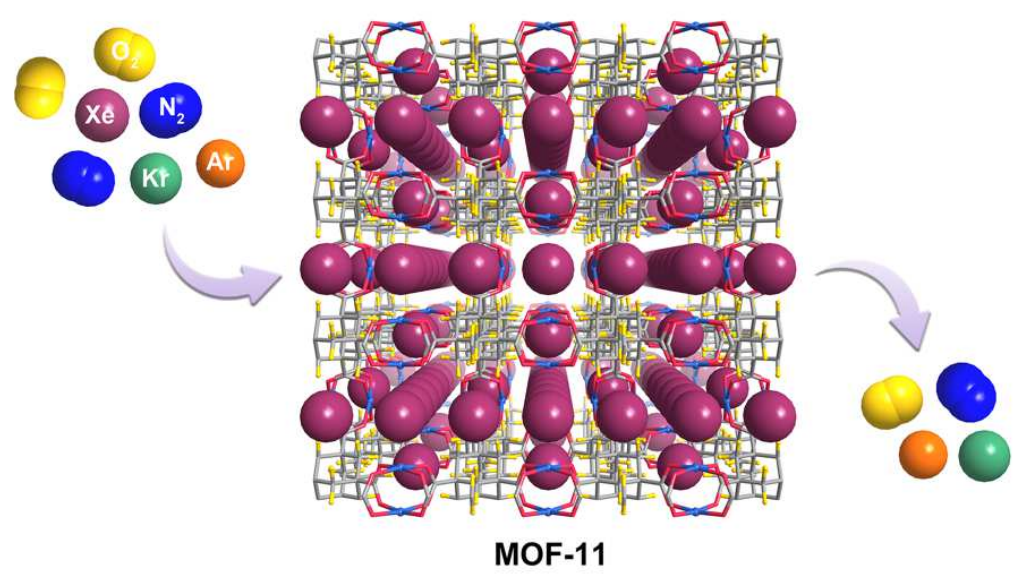




\section{Supplementary Files}

This is a list of supplementary files associated with this preprint. Click to download.

- SupplementaryMaterial0101.pdf 